\title{
Role of Hypothyroidism in Dyslipidaemia and Blood Glucose Regulation
}

\author{
P. Usha Kiran ${ }^{1}$, V. Sandeesha² N. Lakshmana Kumar³ \\ ${ }^{1}$ Associate Professor, Department of Biochemistry, GSL Medical College and General Hospital, \\ Rajahmundry, Andhra Pradesh, India. \\ ${ }^{2}$ Assistant Professor, Department of Biochemistry, GSL Medical College and General Hospital, \\ Rajahmundry, Andhra Pradesh, India. \\ ${ }^{3}$ Professor and HOD, Department of Biochemistry, GSL Medical College and General Hospital, \\ Rajahmundry, Andhra Pradesh, India.
}

ABSTRACT

\section{BACKGROUND}

Hypothyroidism is associated with insulin resistance and hyperlipidaemia. Insulin resistance is the reason behind type 2 diabetes mellitus and is found in mild thyroid dysfunction with increased risk of dyslipidaemia. Prevalence of type 2 diabetes mellitus and cardiovascular risk is more common in hypothyroidism. Hence regular screening of blood glucose and lipid profile in hypothyroidism individuals may prevent dreaded complications. The aim of this study to evaluate the role of thyroid dysfunction on alteration of glucose and lipid metabolism leading to insulin resistance, an important risk factor for cardio vascular diseases.

\section{METHODS}

In this study, we included 50 subjects, aged 25 to 35 years. This is a case control study conducted in the department of Biochemistry. Investigations like fasting and post prandial blood sugar, HbA1c and lipid profile (Cholesterol, Triglycerides, HDL, LDL \& VLDL) were done. Blood pressure was measured. Body weight and height were measured, and BMI was calculated. All the parameters were analysed using XL 640 fully automated random-access analyser. Data was analysed using GraphPad QuickCalcs software.

\section{RESULTS}

The cases were selected based on T4 and TSH concentrations whose values were significantly decreased and elevated respectively. The patients with hypothyroidism exhibited significant increase in concentration of total cholesterol, LDL, fasting blood glucose and HbA1c while HDL $(p<0.05)$ showed a decrease in its concentration in comparison to controls. BMI and diastolic blood pressure showed significant elevation in hypothyroid individuals when compared to controls.

\section{CONCLUSIONS}

It is evident from this study that insulin resistance may lead to T2DM in individuals with thyroid dysfunction. Disturbed lipid metabolism may eventually lead to cardiovascular complications in patients with thyroid dyscrasias.

\section{KEY WORDS}

Hypothyroidism, Lipid Profile, Glycated Haemoglobin, Blood Pressure, BMI
Corresponding Author:

Dr. V. Sandeesha,

D. No. 75-6-34, RK Hospital,

Prakashnagar, Near Anand Sweets,

Rajahmundry-533103,

Andhra Pradesh, India.

E-mail:drsandeesha@gmail.com

DOI: $10.14260 /$ jemds/2019/543

Financial or Other Competing Interests: None.

How to Cite This Article:

Kiran PU, Sandeesha V, Kumar NL. Role of hypothyroidism in dyslipidaemia and blood glucose regulation. J. Evolution Med. Dent. Sci. 2019;8(31):2495-2499, DOI: $10.14260 /$ jemds $/ 2019 / 543$

Submission 28-06-2019,

Peer Review 25-07-2019,

Acceptance 27-07-2019,

Published 05-08-2019. 


\section{BACKGROUND}

Decreased activity of thyroid gland is known as hypothyroidism. Reduced functioning of thyroid gland leads to decreased secretion of hormones like total thyroxine (T4) and triiodothyronine (T3). This decrease in T4 and T3 leads to secondary activation of pituitary gland to release increased levels of serum TSH. Hypothyroidism is contributing to one of the causes of metabolic syndrome which is a clinical syndrome due to slowing down of metabolic activity. ${ }^{1}$ The prevalence of disease ranges from $2 \%$ to $15 \%$ of the population depending on the severity of disease. Women are affected more often than men and both sexes are affected more frequently with increasing age. Clinical symptoms include lethargy, fatigue and cold intolerance. It is associated with insulin resistance and hyperlipidaemia which is proven by different studies. ${ }^{2}$ Thyroid hormones have effect on synthesis and distribution of lipids. In some studies, it was shown that $25 \%$ of the new onset cardiovascular disease (CVD) are due to metabolic syndrome. ${ }^{3}$ Hyperlipidaemia and insulin resistance are the components of metabolic syndrome. Thyroid hormones have regulatory effect on blood pressure along with glucose and lipid metabolism which may be considered as the risk factors for cardiovascular morbidity in hypothyroidism. ${ }^{4}$ Almost one-third of the people are in iodine deficiency state. The prevalence of goiter has gone up to $80 \%$ in these endemic areas of iodine deficiency. The most commonly encountered thyroid disorders in these areas are autoimmune diseases like primary atrophic hypothyroidism, Hashimoto's thyroiditis and Graves' disease. ${ }^{5}$ The role of thyroid hormones in glucose homeostasis has been established long back. ${ }^{6}$ In 1927, Coller and Huggins had proved the association between hyperthyroidism and diabetes. This association has been proved experimentally in hyperthyroid patients with diabetes in whom glucose homeostasis has been restored after surgical removal of parts of thyroid gland. ${ }^{7}$ Even morbid obesity is related to thyroid activity which is another component of metabolic syndrome.

\section{METHODS}

The present study is a case control study conducted in the department of biochemistry. Institutional ethical committee clearance was taken. The total size of the sample is 75 out of which 50 cases and 25 controls where their age and sex were matched and compared. The sample size was small as it was done over a week time during the endocrinologist consultation days. The control sample size though small the results were comparable; hence a smaller group was taken as control group. Venous blood samples were collected to analyse the thyroid profile, fasting and post prandial blood glucose levels, glycated haemoglobin and lipid profile. The sample was collected after taking the consent both from cases and controls. Thyroid hormones were analysed using Vidas. All the other parameters were analysed using XL640 fully automated random-access analyser. Height and weight were measured, and BMI was calculated. Blood pressure was measured for both cases and controls. History of the current illness, medication, alcohol consumption and cigarettes smoking were noted.

\section{Inclusion Criteria}

Individuals having hypothyroidism diagnosed based on thyroid profile and clinical features with an age group between 25-35 years were taken as cases. Individuals with normal thyroid profile in the age group of 25-35 years were taken as controls.

\section{Exclusion Criteria}

Persons with any acute or chronic illness like diabetes, hypertension, familial hyperlipidaemia.

\section{Biochemical Analysis}

All the parameters were analysed using ERBA system pack reagents on Erba XL-640 fully automated analyser. Glucose was determined by using GOD-POD method, Cholesterol by CHOD-PAP method, Triglycerides by GPO method \& HDL by PVS/PEGME precipitation method and HbA1c by immunoturbidimetry. Thyroid profile was determined by using Fluorescent Immuno Assay on VIDAS.

\section{Statistical Analysis}

Data were computer analyzed using GraphPad QuickCalcs software. The independent sample t-test procedure was used to compare different continuous variables between the two groups separated based on thyroid profile. Descriptive data was presented as mean \pm standard deviation. For all statistical analysis, $\mathrm{p}<0.05$ was considered as statistically significant.

\section{RESULTS}

The demographic characteristics of study population and the results were shown as follows.

\begin{tabular}{|c|c|c|c|}
\hline Parameter & $\begin{array}{c}\text { Cases } \\
(\text { Mean } \pm \text { SD })\end{array}$ & $\begin{array}{c}\text { Controls } \\
(\text { Mean } \pm \text { SD) }\end{array}$ & $\begin{array}{c}\mathbf{p} \\
\text { Value }\end{array}$ \\
\hline Age & $31.10 \pm 6.49$ & $29.84 \pm 8.22$ & 0.4713 \\
\hline BMI & $28.16 \pm 4.26$ & $25.74 \pm 4.31$ & 0.0241 \\
\hline Systolic blood pressure & $127.60 \pm 10.67$ & $126.72 \pm 10.47$ & 0.7357 \\
\hline Diastolic blood pressure & $94.00 \pm 4.92$ & $79.04 \pm 6.82$ & 0.0001 \\
\hline \multicolumn{4}{|c|}{ Table 1. Showing Demographic Characters } \\
\hline
\end{tabular}

\begin{tabular}{|c|c|c|c|}
\hline Parameter & $\begin{array}{c}\text { Cases } \\
\text { (Mean } \pm \text { SD) }\end{array}$ & $\begin{array}{c}\text { Controls } \\
\text { (Mean } \pm \text { SD) }\end{array}$ & $\begin{array}{c}\text { p } \\
\text { Value }\end{array}$ \\
\hline Triiodothyronine (T3) & $2.25 \pm 2.54$ & $1.83 \pm 0.59$ & 0.402 \\
\hline Thyroxine (T4) & $72.30 \pm 38.01$ & $101.00 \pm 25.32$ & 0.0011 \\
\hline Thyroid Stimulating Hormone & $21.10 \pm 26.91$ & $2.52 \pm 1.17$ & 0.0010 \\
\hline \multicolumn{4}{|c|}{ Table 2. Showing Thyroid Profile } \\
\hline From table 2 it is seen that total T4 is significantly lower and TSH is significantly \\
higher in cases compared to controls indicating hypothyroidism. \\
\hline
\end{tabular}

\begin{tabular}{|c|c|c|c|}
\hline Parameter & $\begin{array}{c}\text { Cases } \\
\text { (Mean } \pm \text { SD) }\end{array}$ & $\begin{array}{c}\text { Controls } \\
\text { (Mean } \pm \text { SD) }\end{array}$ & $\begin{array}{c}\mathbf{p} \\
\text { Value }\end{array}$ \\
\hline Total cholesterol & $224.04 \pm 29.86$ & $166.64 \pm 21.03$ & 0.0001 \\
\hline LDL Cholesterol & $155.24 \pm 30.73$ & $96.04 \pm 21.03$ & 0.0001 \\
\hline Triglycerides & $166.00 \pm 24.31$ & $160.00 \pm 19.66$ & 0.2880 \\
\hline HDL Cholesterol & $33.86 \pm 2.62$ & $39.04 \pm 3.05$ & 0.0001 \\
\hline \multicolumn{4}{|c|}{ Table 3. Showing Lipid Profile } \\
\hline $\begin{array}{l}\text { From table 3 it is shown that total cholesterol and LDL cholesterol are higher in cases } \\
\text { when compared to controls whereas HDL cholesterol is significantly lower in cases } \\
\text { when compared to controls indicating hypothyroidism has its effect on lipid profile. }\end{array}$ \\
\hline
\end{tabular}




\begin{tabular}{|c|c|c|c|}
\hline Parameter & $\begin{array}{c}\text { Cases } \\
\text { (Mean } \pm \text { SD) }\end{array}$ & $\begin{array}{c}\text { Controls } \\
\text { (Mean } \pm \text { SD) }\end{array}$ & $\begin{array}{c}\text { p } \\
\text { Value }\end{array}$ \\
\hline Fasting plasma glucose & $105.40 \pm 20.42$ & $92.68 \pm 4.85$ & 0.0031 \\
\hline Post prandial plasma glucose & $141.90 \pm 20.69$ & $143.40 \pm 16.09$ & 0.7519 \\
\hline Glycated haemoglobin (HbA1c) & $6.136 \pm 0.76$ & $5.312 \pm 0.94$ & 0.0001 \\
\hline Table 4. Showing Fasting Plasma Glucose, Post Prandial Plasma \\
Glucose and Glycated Haemoglobin \\
\hline
\end{tabular}

\section{DISCUSSION}

In the present study, the majority of the cases and the controls were seen in the age group of 25-35 years. Serum TSH and T4 were significantly higher in the case group ( $p=0.001$ ) compared with the control group. But the T3 do not show significant difference between the two groups. The study also showed female predominance with $82 \%$ ( 41 out of 50 ) versus male, 26 (13 out of 100) of total participants. There was no statistically significant difference between the case group and the control group with regard to age and sex. So, we can say that the levels of lipid profile and other parameters in both the groups were not affected by age or sex. The prevalence of hypothyroidism is around $20 \%{ }^{8}$ The relationship between hypothyroidism and obesity was not established clearly so far. ${ }^{9}$ Few studies have attributed the obesity in hypothyroidism to be due to the deficit in resting energy expenditure. But some other studies have found that thyroid function is normal in most of the obese individuals. It's a known fact that leptin, a peptide hormone produced by adipose tissue, has a role in the pathophysiology of obesity. It was found that hypothyroid individuals have higher leptin levels when compared to euthyroid subjects with same body mass index (BMI) ${ }^{10}$ but still some studies show that deficit in resting energy expenditure may be one of the causes for obesity in hypothyroid patients. The reduced Resting Energy Expenditure is due to reduced peripheral effect of thyroid hormones.(11-13) This can be evidenced from this study with significant $(p=0.021)$ elevation in BMI in hypothyroid individuals when compared to controls.

The study also shows that the subjects with hypothyroidism showed significant $(\mathrm{p}>0.0001)$ elevation in the concentrations of total cholesterol, LDL cholesterol and decrease in HDL cholesterol but there is no significant difference in triglyceride levels when compared to controls. Thyroid hormones induce HMG CoA reductase which is the rate limiting enzyme of cholesterol synthesis. This results in decreased synthesis of cholesterol in hypothyroidism. However, serum cholesterol levels are conversely increased in hypothyroidism. This is because thyroid hormone may simultaneously affect metabolism of LDL cholesterol.14 Approximately $3 \%$ of thyroxine (T4) is bound to lipoproteins, $92 \%$ to HDL and $6.7 \%$ to LDL. ${ }^{15}$ The LDL bound T4 is engulfed by the LDL receptor and helps in its degradation. ${ }^{16}$ This results in predominant catabolism without any effect on synthesis of LDL $^{17}$ Plasma HDL concentrations have been reported to be either normal or even elevated in severe hypothyroidism. ${ }^{18}$ These conflicting results arising because thyroid hormones regulate the activity of CETP and HL. ${ }^{19}$ Cholesterol esters are transferred from HDL2 to VLDL, IDL, and inversely from triglyceride to HDL2 by CETP. ${ }^{20}$ HDL2 is then converted to HDL3 by HL. CEPT and more specifically HL seem to be dependent on the status of thyroid function, and they are decreased in hypothyroidism. ${ }^{21}$ Thyroid hormones help in regulation of glucose levels. They have a role in development of insulin resistance by effecting circulating insulin levels, counter regulatory hormones, intestinal absorption, hepatic production and uptake of glucose by peripheral tissues. Thyroid hormones act differently on different tissues of insulin action like liver, skeletal muscles and adipose tissue. Thyroid hormones regulate the expression of genes for GLUT-4 involved in glucose transport and enzymes like phosphoglycerate kinase involved in glycolysis. This action of thyroid is synergistic with insulin in facilitating glucose transport and utilization by peripheral tissue. ${ }^{22}$ In hypothyroidism, because of altered metabolism of lipid in adipose tissue as seen in obesity, binding of insulin to insulin receptor decreases. ${ }^{23}$ There is also Impaired translocation of GLUT-4 glucose transporters on plasma membrane resulting in decreased glucose uptake in muscles and adipose tissue. But the results from our study showed only significant $(0.003)$ elevation in fasting blood glucose in cases when compared to controls while the post prandial blood glucose do not significant (0.75) difference between the two groups. Even the fasting plasma glucose though elevated when compared to controls the mean value (105) has just crossed the upper normal limit. This indicates an impaired state with a chance of development of diabetes in future as the value is significantly high compared to controls.

$\mathrm{HbA1c}$ is one of the accepted investigation for diagnosis and monitoring of diabetes according to American Diabetes Association (ADA). ${ }^{24}$ The HbA1c concentration gives the blood glucose concentration over a period of time rather than at a particular point of time as HbA1c concentration is dependent on the life span of the erythrocytes. Hence HbA1c levels may vary with alteration in the turnover of erythrocytes though blood glucose levels may not be altered. ${ }^{25}$ so there may be possibility of false high or low values in spite of normal glucose levels. Recent studies have shown that there is a false elevation of HbA1c levels in hypothyroidism. ${ }^{26}$ Normocytic normochromic anaemia commonly seen in hypothyroidism may be simply an iron deficiency anaemia due to nutritional deficiency or it may be secondary to hypothyroidism itself. ${ }^{27}$ This is because reduced thyroid hormone levels repress the bone marrow resulting in decreased erythrocyte production. This reduced erythrocyte life span may be responsible for false elevation in HbA1C levels. ${ }^{28-30}$ The value of HbA1c in the present study showed significant (0.0001) elevation in the cases when compared to controls but the value (6.1) does not cross the cut-off value of diagnosing diabetes. Even the value is not corresponding to the blood glucose values. It is inconclusive from this study whether to attribute the elevated HbA1c to impending diabetes or it is a spurious elevation as haemoglobin values were not evaluated to compare. Instead of HbA1c, we might have taken insulin levels which would be a more reliable parameter to assess glucose status. This finding has been elaborated by a study done by Al-Sayed A et al, in which they found that the insulin levels were significantly higher in the Subclinical hypothyroidism group comparable to the normal control. ${ }^{31}$ But in this study insulin levels could not be evaluated which is a drawback for this study.

Long-standing hypothyroidism is associated with several cardiovascular manifestations. Such as it may cause decreased intravascular volume, increased systemic vascular resistance, and thereby hypertension. ${ }^{32}$ Altered cardiac performance is 
most probably due to changes in the peripheral circulation. Hypertension especially diastolic hypertension is more common in hypothyroidism which may contribute to approximately $20 \%$ of hypothyroid patients as seen in this study where there is a significant (0.0001) elevation in diastolic blood pressure in cases when compared to controls while there is no (0.73) significant difference in systolic blood pressure between the two groups. ${ }^{33}$ Hypertension and dyslipidaemia in thyroid failure together may accelerate the process of atherosclerosis. It has been demonstrated that thyroid hormone replacement therapy in these individuals lead to a significant improvement of cardiovascular performance. $^{34}$ Optimum hormone replacement over a prolonged time course may help in decrease of hypertension. 35

\section{CONCLUSIONS}

Hypothyroidism results in dyslipidaemia. This dyslipidaemia may in turn affect the endothelium function. It may ultimately result in diastolic hypertension and cardiovascular disease. Insulin resistance which is the pathophysiological process of type 2 diabetes mellitus, is frequently found in thyroid dysfunction. The development of insulin resistance leads to many metabolic abnormalities apart from diabetes. Hence nowadays there is more focus on the influence of thyroid hormones on insulin levels. Thyroid dysfunction leads to alteration in glucose and lipid homeostasis which may in turn lead to insulin resistance. Insulin resistance is an important risk factor for cardiovascular diseases. Early detection of insulin resistance and prompt intervention in hypothyroid patients will be helpful in decreasing cardiovascular morbidity and mortality. Treatment of diabetes alone will not be able to resolve insulin resistance completely in hypothyroid individuals. Treatment of hypothyroidism along with diabetes will only take care of total insulin resistance in those diabetic individuals with hypothyroidism.

\section{REFERENCES}

[1] Roos A, Bakker SJ, Links TP, et al. Thyroid function is associated with components of the metabolic syndrome in euthyroid subjects. J Clin Endo Metabolism 2007;92(2):491-6.

[2] Bakker SJ, Ter Maaten JC, Popp-Snijders C, et al. The relationship between thyrotropin and low density lipoprotein cholesterol is modified by insulin sensitivity in healthy euthyroid subjects. Clin Endocrinol Metabolism 2001;86(3):1206-11.

[3] Kutty KM, Bryant DG, Farid NR. Serum lipids in hypothyroidism-a re-evaluation. J Clin Endocrinol Metab 1978;46(1):55-6.

[4] Haghi AR, Solhjoo M, Tavakoli MH, et al. Correlation between subclinical hypothyroidism and dyslipidaemia. Iranian Journal of Pathology 2017;12(2):106-11.

[5] Vanderpump MP. The epidemiology of thyroid disease. $\mathrm{Br}$ Med Bull 2011;99(1):39-51.

[6] Yadav P, Kaushik GG, Sharma S. Importance of screening Type-II diabetics for thyroid dysfunction and dyslipidaemia. International Journal of Biochemistry and Biophysics 2015;3(2):7-12.

[7] Coller FA, Huggins CB. Effect of hyperthyroidism upon diabetes mellitus: striking improvement in diabetes mellitus from thyroidectomy. Ann Surg 1927;86(6):87784.

[8] Sawin CT, Castelli WP, Hershman JM, et al. The aging thyroid. Thyroid deficiency in the Framingham study. Arch Intern Med 1985;145(8):1386-8.

[9] Goran MI. Energy metabolism and obesity. Med Clin North Am 2000;84(2):347-62.

[10] Leonhardt U, Ritzel U, Schafer G, et al. Serum leptin levels in hypo- and hyperthyroidism. J Endocrinol 1998;157(1):75-9.

[11] Carpenter WH, Fonong T, Toth MJ, et al. Total daily energy expenditure in free-living older African-Americans and Caucasians. Am J Physiol 1998;274(1):E96 -101.

[12] Foster GD, Wadden TA, Vogt RA. Resting energy expenditure in obese African American and Caucasian women. Obes Res 1997;5(1):1-8.

[13] Wurmser H, Laessle R, Jacob K, et al. Resting metabolic rate in preadolescent girls at high risk of obesity. Int J Obes Relat Metab Disord 1998;22(8):793-9.

[14] Friis T, Pedersen LR. Serum lipids in hyper - and hypothyroidism before and after treatment. Clin Chim Acta 1987;162(2):155-63.

[15] Benvenga S, Gregg RE, Robbins J. Binding of thyroid hormones to human plasma lipoproteins. J Clin Endocrinol Metab 1988;67(1):6-16.

[16] Benvenga S, Robbins J. Enhancement of thyroxine entry into low density lipoprotein (LDL) receptor-competent fibroblasts by LDL: an additional mode of entry of thyroxine into cells. Endocrinology 1990;126(2):933-41.

[17] Staels B, van Tol A, Chan L, et al. Alterations in thyroid status modulate apolipoprotein, hepatic triglyceride lipase and low density lipoprotein receptor in rats. Endocrinology 1990;127(3):1144-52.

[18] Scottolini AG, Bhagavan NV, Oshiro TH, et al. Serum highdensity lipoprotein cholesterol concentrations in hypoand hyperthyroidism. Clin Chem 1980;26(5):584-7.

[19] Tan KC, Shiu SW, Kung AW. Plasma cholesteryl ester transfer protein activity in hyper - and hypothyroidism. J Clin Endocrinol Metab 1998;83(1):140-3.

[20] Lagrost L. Regulation of cholesteryl ester transfer protein (CETP) activity: review of in vitro and in vivo studies. Biochem Biophys Acta 1994;1215(3):209-36.

[21] Kussi T, Saarinen P, Nikkila EA. Evidence for the role of hepatic endothelial lipase in the metabolism of plasma high density lipoprotein2 in man. Atherosclerosis 1980;36(4):589-93.

[22] Gould GW, Holman GD. The glucose transporter family: structure, function and tissue specific expression. Biochem J 1993;295(Pt 2)329-41.

[23] Turner RC, Holman RR, Matthews D, et al. Insulin deficiency and insulin resistance interaction in diabetes: estimation of their relative contribution by feedback analysis from basal plasma insulin and glucose concentrations. Metabolism 1979;28(11):1086-96.

[24] American Diabetes Association. Diagnosis and classification of diabetes mellitus. Diabetes Care 2011;34(Suppl 1):S62-S9. 
[25] Gram-Hansen P, Eriksen J, Mourits-Andersen T, et al. Glycosylated haemoglobin (HbA1c) in iron and vitamin B12 deficiency. J Int Med 1990;227(2):133-6.

[26] Vij V, Chitnis P, Gupta VK. Evaluation of thyroid dysfunction among type 2 diabetic patients. Int J Pharm Bio Sci 2012;2(4):150-5.

[27] Hardikar PS, Joshi SM, Bhat DS, et al. Spuriously high prevalence of pre-diabetes diagnosed by HbA1c in young Indians partly explained by haematological factors and iron deficiency anemia. Diabetes Care 2012;35(4):797802.

[28] Horton L, Coburn RJ, England JM, et al. The hematology of hypothyroidism. Q J Med 1976;45(177):101-23.

[29] Das KC, Mukherjee M, Sarkar TK, et al. Erythropoiesis and erythropoietin in hypo- and hyperthyroidism. J Clin Endocrinol Metab 1975;40(2):211-20.
[30] Fein HG, Rivlin RS. Anaemia in thyroid diseases. Med Clin North Am 1975;59(5):1133-45.

[31] Al Sayed A, Al Ali N, Bo Abbas Y, et al. Subclinical hypothyroidism is associated with early insulin resistance in Kuwaiti women. Endocr J 2006;53(5):653-7.

[32] Franklyn JA, Daykin J, Betteridge J, et al. Thyroxine replacement therapy and circulating lipid concentrations. Clin Endocrinol (Oxf) 1993;38(5):453-9.

[33] Klein I. Thyroid hormone and the cardiovascular system. Am J Med 1990;88(6):631-7.

[34] Klein I, Ojamaa K. Clinical review 36: cardiovascular manifestations of endocrine disease. J Clin Endocrinol Metab 1992;75(2):339-42.

[35] Klemperer JD, Ojamaa K, Klein I. Thyroid hormone therapy in cardiovascular disease. Prog Cardiovasc Dis 1996;38(4):329-36. 